\title{
La correspondencia de Alma M. Reed \\ y Felipe Carrillo Puerto: \\ UNA MICRO-HISTORIA PASIONAL Y POLÍTICA
}

\author{
The Correspondence of Alma M. Reed \\ and Felipe Carrillo Puerto: \\ a Passional and Political Micro-History
}

Michael Schuessler ${ }^{1}$

Resumen: En algunos casos, la información procedente de fuentes historiográficas "alternativas" puede iluminar un momento nacional de gran relevancia, y en este ensayo expondré cómo los datos provenientes de la correspondencia personal entre dos individuos que se encontraron inmiscuidos en un momento histórico posibilitan el rellenar los intersticios - a veces invisibles - que se encuentran entre la macro y la micro historia de una región geopolítica y su subsiguiente historia oficial, que en este caso se presentan por medio de la observación de una pareja clave y a su vez inopinada: la periodista norteamericana Alma M. Reed (1889-1966) y su prometido, el gobernador socialista de Yucatán, Felipe Carrillo Puerto (1874-1924).

Palabras clave: Yucatán, Revolución mexicana, correspondencia, periodismo, relaciones México-Estados Unidos.

\footnotetext{
${ }^{1}$ Universidad Autónoma Metropolitana, Cuajimalpa. Doctor en Lenguas y literaturas hispánicas por la Universidad de California, Los Ángeles. Líneas de investigación: biografía y testimonio en las Américas, redes culturales e intelectuales en las Américas, historia cultural de América Latina. Correo electrónico: mschuess@gmail.com Fecha de recepción: 1211 15; Fecha de aceptación: 050216.
}

(cc) EY-NC-ND Páginas 79-106. 
Abstract: In certain cases, information gleaned from "alternative" historiographical sources can illuminate a time of great national importance and in this essay I will discuss how data obtained from the personal correspondence between two individuals who were intimately tied to a historic moment can illuminate a period of national and political interest. This information helps to fill the gaps, at times invisible, that are to be found between the macro and the micro history of a geopolitical region and its subsequent official story, in this case, the information is provided through the observations of US journalist Alma M. Reed (1889-1966) regarding the activities and ideals of her fiancée, the Socialist governor of Yucatan, Felipe Carrillo Puerto (1874-1924).

Keywords: Yucatan, Mexican Revolution, correspondence, journalism, Mexico-US relations.

Si bien la transcripción de la memoria individual y colectiva ha dado sus frutos en la forma de crónicas, anales, relaciones e historias "oficiales" de conquistas, expediciones y batallas, los géneros epistolar y autobiográfico, por definición personales, íntimos, más cercanos - a primera vista - al siglo XIX que a los anteriores, también han brindado un corpus de información para mejor entrever los detalles que, en muchas ocasiones, la historia oficial suele callar, ignorar o desatender. De hecho, se puede argumentar que tales documentos privados, introspectivos, de naturaleza subjetiva — diarios, cartas, autobiografías - sirven precisamente para llenar los huecos que ha dejado la historiografía épica, que procura evidenciar e insertar los grandes acontecimientos del pasado dentro de una visión global de ciertos eventos históricos consagrados a través del tiempo. En el caso del México postrevolucionario — nacionalista, indigenista, introspectivocontamos con muchas historias de esta índole cuyos datos, si bien relevantes, en muchas ocasiones se pueden — se deben - matizar por medio de una visión inmediata, personal, incluso subjetiva, procedente de un testigo ocular de los hechos bajo escrutinio. 
Para revelar sólo una faceta de cómo la información procedente de estas fuentes "alternativas" puede iluminar un momento nacional muy relevante, en este ensayo expondré datos provenientes de la correspondencia personal entre dos individuos que se encontraron inmiscuidos en un momento histórico, con los que rellenar los intersticios - a veces invisibles- que se encuentran entre la macro y la micro historia de una región geopolítica y su subsiguiente historia oficial, que en este caso se presentan por medio de la observación de una pareja clave y a su vez inopinada: la periodista norteamericana Alma M. Reed (1889-1966) y su prometido, el gobernador socialista de Yucatán, Felipe Carrillo Puerto (1874-1924).

Figura 1. Alma M. Reed y Felipe Carrillo Puerto en Yucatán.

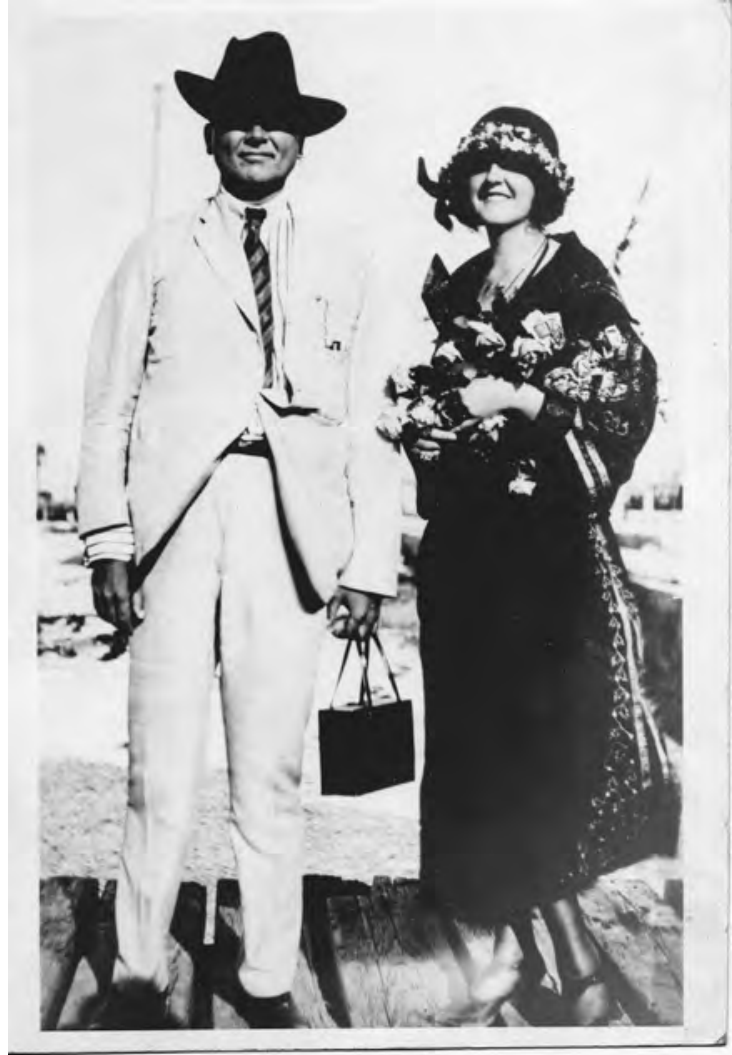

Fuente: Colección personal 
Antes de detallar algunos de los resquicios que, bajo escrutinio, se desprenden de su correspondencia epistolar que duró menos de un año, será oportuno presentar varios datos biográficos de los protagonistas de estas historias y, de paso, comentar las circunstancias extraordinarias que me llevaron a descubrir dicha correspondencia, amén de la autobiografía inédita preparada por Reed en los últimos años de su vida, que nunca llegó a la imprenta por la repentina muerte de su autora el 20 de noviembre de 1966.

\section{"La Peregrina de Ojos Claros y Divinos"}

Alma Marie Sullivan nació en San Francisco, California, en 1889, y fue la mayor de ocho hermanos de una familia irlandesa-escocesa. En 1913, a la edad de 24 años, ingresó como periodista al San Francisco Call, donde colaboró con el seudónimo de "Mrs. Goodfellow". Allí publicaba una columna semanal dedicada a los problemas enfrentados por los sectores marginados de la población local. En este contexto, Reed entró en contacto con la comunidad mexicana de San Francisco y fue precisamente su celebrada defensa del joven trabajador mexicano Simón Ruiz, sentenciado a la horca, acusado de haber asesinado a su patrón, lo que sellaría para siempre su relación con México. Gracias a los esfuerzos de "Mrs. Goodfellow", el joven salvó la vida y, como resultado, en California se instituyó el Saylor Bill, figura jurídica que hasta la fecha prohíbe la ejecución de menores de edad en aquel estado. $\mathrm{Su}$ incesante defensa de los derechos de los mexicanos que en aquel entonces vivían y trabajaban en los Estados Unidos - muchas veces bajo condiciones injustas y precarias - preludia una realidad social y política que no ha sido resuelta de manera tolerable hasta la fecha.

Para agradecer su exitosa defensa de Simón Ruiz en las páginas del mencionado periódico, Reed fue invitada a México por el gobierno de Álvaro Obregón, quien la recibió en su residencia oficial, en ese entonces el Castillo de Chapultepec. Llegó en septiembre de 1922, después de un largo viaje en tren desde Ciudad Juárez, toda una hazaña para una mujer sola en aquel entonces. Durante su primera estancia en la ciudad de México, la llevaron a conocer muchas de las atracciones de la capital, donde atestiguó algunas de las actividades producto de la 
política cultural derivada de la Revolución mexicana. En este contexto conoció a José Clemente Orozco, a quien observó mientras pintaba sobre los muros de los patios de la Escuela Nacional Preparatoria, ubicada en el antiguo Colegio de San Ildefonso. Su encuentro con Orozco fue breve pero sembró las semillas de una relación profesional y personal que resultaría fundamental para el reconocimiento del pintor jalisciense en Estados Unidos. La fascinación de Reed con México y su cultura ya se vislumbra en una de las primeras entrevistas que concedió al diario Excélsior en septiembre de 1922, donde señala que "México debería ser la Meca de los artistas de todo el mundo: aquí cada objeto y cada escena es razón suficiente para el arte y la belleza”.

En respuesta a la publicidad generada por sus logros periodísticos en San Francisco y México, Adolph Ochs, editor del rotativo estadounidense The New York Times, ofreció a Reed enviarla de regreso a México, en esta ocasión para cubrir la expedición arqueológica a las ruinas mayas de Chichén Itzá organizada por el Instituto Carnegie y dirigida por el Dr. Sylvanus G. Morley. El plan de Morley era excavar en las ruinas de esta ciudad emblemática de la cultura maya-tolteca ubicada dentro de los terrenos de la hacienda que, en ese momento, era propiedad del explorador y arqueólogo estadounidense, Edward H. Thompson. Como lo relata Reed en sus memorias, le resultó "simpática" a Thompson, a quien ella también admiraba por su aparente profesionalismo y capacidad de trabajo. En muy corto tiempo la hizo su confidente y le reveló que, a lo largo de los años, él había recuperado una gran cantidad de piezas arqueológicas del fondo del Cenote Sagrado de Chichén Itzá y que, poco a poco, había enviado muchas de ellas al Museo Peabody de la Universidad de Harvard y al Museo Field de Chicago por conducto de colegas y amigos.

Al parecer, el mismo Thompson aprovechaba sus viajes a Estados Unidos para acarrear maletas que contenían objetos prehispánicos de valor incalculable, la mayoría sustraída por medio de la "arqueología subacuática” que él había desarrollado para excavar con más cuidado las profundidades del Cenote Sagrado, ubicado en aquel momento en su hacienda. La noticia del "acarreo hormiga" del patrimonio mexicano llevado a cabo por el arqueólogo y sus amigos apareció como noticia 
exclusiva y con la autorización de Thompson en The New York Times el 8 de abril de 1923, bajo el título: "El cenote de los sacrificios humanos de los mayas". Curiosamente, a pesar de su incitante título, la nota no tuvo la resonancia que Reed esperaba; ni siquiera parece haber consternado a su amado Felipe Carrillo Puerto, quien había abandonado el Palacio de Gobierno en Mérida para que éste sirviera como museo arqueológico que albergara la creciente colección de piezas mayas que le llevaban los campesinos locales.

Según las investigaciones del Dr. Pedro Castro, tres años más tarde, en 1926, este asunto se convertiría en un escándalo binacional gracias, al menos en parte, a la publicación del libro de T.A. Willard intitulado The City of the Sacred Well: Being a Narrative of the Discoveries and Excavations of Edward Herbert Thompson in the Ancient City of Chichen Itza, cuando México exigió la repatriación del tesoro expoliado o, en su defecto, un cuantioso pago como indemnización. ${ }^{2}$ Sin embargo, no sería hasta 1946 — veinte años después de la demanda original—cuando el Museo Peabody de la universidad de Harvard devolviera una parte de este patrimonio mal habido, aunque, eso sí, a cambio de otras piezas provenientes de museos mexicanos. Según Castro (2014b), el agente del gobierno mexicano:

... reclamó la devolución de las piezas extraídas del Cenote Sagrado durante 1904, 1905 y 1906. Esta demanda fue promovida el 20 de septiembre de 1926, pidiendo se condenara al demandado el pago del precio de tales objetos, ascendente a la suma de 1,036,410 pesos, en que se señaló la cuantía de la responsabilidad civil por el delito de robo, que cometió al apoderarse de los objetos arqueológicos pertenecientes a la nación. En cuanto supo que se iniciaría un proceso penal y civil en su contra, Thompson optó por huir como cualquier delincuente; fletó una goleta, y con otras veintiséis personas, escasos víveres, sin velas e instrumentos náuticos, se hizo a la mar... (Castro, 2014b: 10).

\footnotetext{
${ }^{2}$ Para un detallado resumen de la historia de Edward Thompson en Chichén Itzá, ver el artículo de Pedro Castro titulado "La aproximación simbólica de lo indígena por el estado posrevolucionario: el caso del cenote sagrado de Chichén Itzá", citado en la bibliografía que acompaña este artículo.
} 
Con la muerte del "arqueológico-saqueador", el proceso penal “...se extinguió el 21 de agosto de 1935, ...cuando la Procuraduría General de la República se desistió de la acción penal y solicitó el sobreseimiento del proceso. La acción civil, sin embargo, continuó en contra de la sucesión de sus bienes" (Castro, 2014b, 12).

\section{"El Dragón Rojo con Ojos de Jade"}

Felipe Carrillo Puerto nació en Motul, Yucatán, en 1874, hijo de Justiniano Carrillo Pasos y Adelaida Puerto Solís. A pesar de su estatura y del color verde de sus ojos, se decía que era descendiente de Nachi Cocom, el último cacique indígena de la federación de Mayapán que luchó en contra de la invasión española a mediados del siglo XVI. En todo caso, luego de haber pasado la mayor parte de su niñez en el campo, en donde entró en contacto directo con los campesinos, fundamentalmente indígenas, Carrillo Puerto aprendió el maya yucateco a la perfección e incluso, durante su juventud, tradujo la Constitución mexicana a este idioma para que así la mayoría yucateca que no hablaba español pudiera conocer sus derechos constitucionales.

Al llegar a la gubernatura de Yucatán el primero de febrero de 1922, Felipe Carrillo Puerto, quien había luchado al lado de Emiliano Zapata en el estado de Morelos, hizo enormes esfuerzos para modernizar su estado, que tan apartado estaba de la capital y cuya clase privilegiada de hacendados pertenecía a la denominada "Casta Divina". Esta oligarquía terrateniente yucateca se resistió a aceptar la reforma agraria puesta en práctica por el gobierno estatal porque afectaba sus latifundios, y rechazaba igualmente otros avances sociales que encabezó el gobernador Carrillo Puerto, como la creación de las Ligas Feministas, impulsadas por Elvia Carrillo Puerto, la hermana de Felipe, por medio de las cuales se instituyó el programa de planeación familiar, que vino a ser el primero en el hemisferio occidental, además de otorgar a la mujer yucateca el derecho al sufragio, con lo cual esa entidad federativa se adelantó muchos años al resto de la República mexicana. 
Figura 2. Alma Reed con Elvia Carrillo Puerto, hermana del gobernador, y Raquel Dzib Cicero, de la Liga Feminista del Sureste.

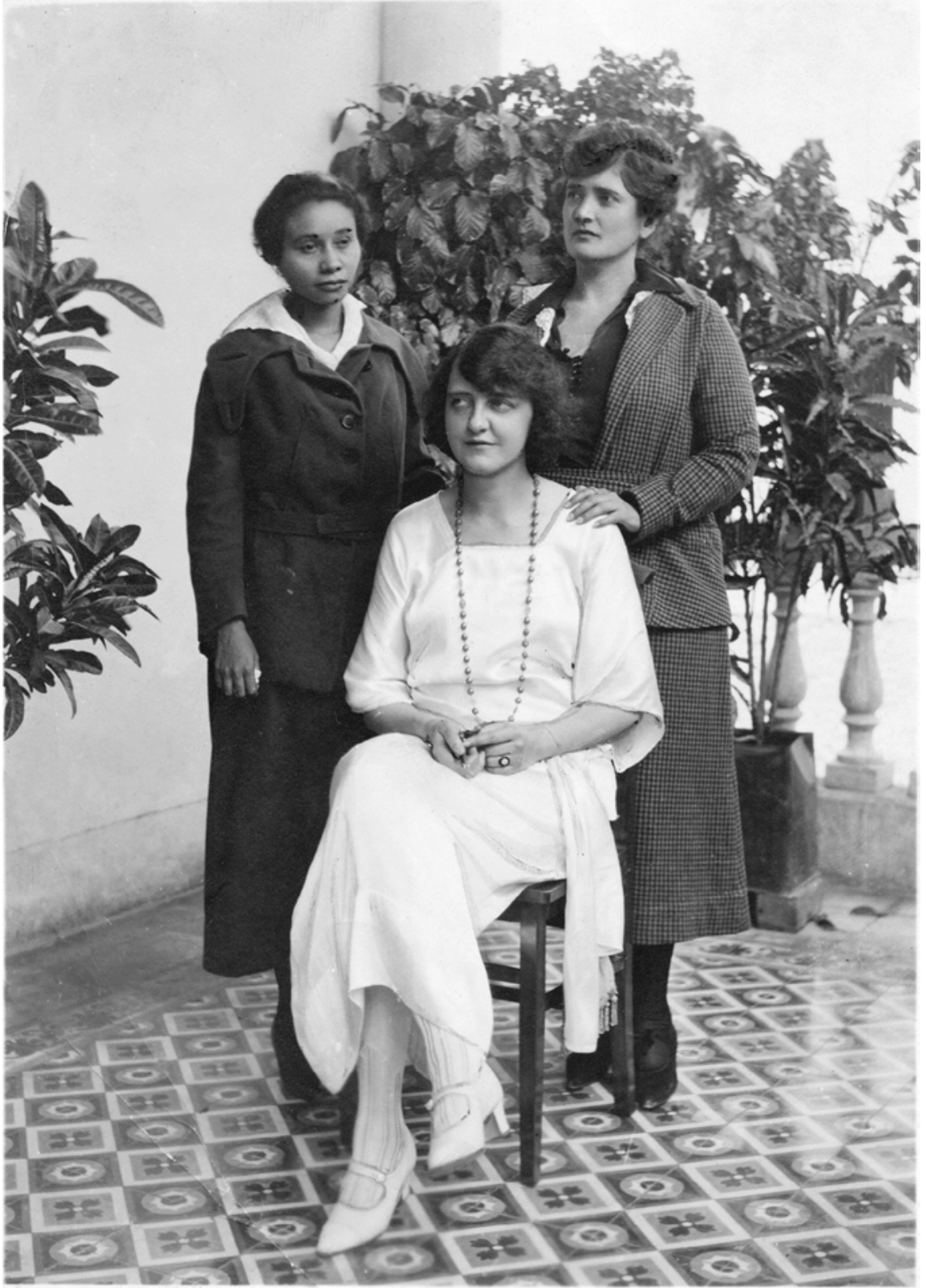

Fuente: Colección personal 
Carrillo Puerto también fundó más de cuatrocientas escuelas locales para educar a los mayas que, hasta entonces, vivían en condiciones deplorables de semi-esclavitud impuestas por el sistema de servicio por endeudamiento - de las tiendas de raya, principalmente - imperante en todas las haciendas mexicanas. En un acto de reivindicación social que provocaba al statu quo, el gobernador socialista decidió reinstaurar el sistema de ejidos, con el argumento de que la tierra de Yucatán le pertenecía a sus habitantes por derecho legal de nacimiento. También reformó el sistema carcelario y construyó caminos desde Mérida hacia varios pueblos con el propósito de que los campesinos pudieran transportar sus mercancías al mercado con mayor facilidad.

Alma Reed conoció por primera vez a Carrillo Puerto en una recepción oficial brindada a los científicos y exploradores estadounidenses, llamados "yucatólogos" — en el medio local—, que integraban la expedición arqueológica que ella cubría como reportera. Luego de ser presentada al gobernador Carrillo, la periodista se acercó al general brigadier William Barclay Parsons, miembro de la junta directiva del Instituto Carnegie y el integrante de mayor jerarquía en el grupo, para comentarle la impresión que le había provocado el gobernador. Parsons, un ingeniero de vías férreas y creador del sistema del tren subterráneo de Nueva York, supo expresar la reacción de asombro que era evidente en todos sus compañeros expedicionarios al murmurar al oído de Reed: “-Éste es el dragón rojo más atractivo que yo haya visto en cualquiera de mis safaris... ¿Qué le parece a usted, jovencita? Con total convicción y sin dudarlo, respondí: -Él es mi idea de un dios griego" (Reed, 2006: 69). Por su parte, el amor que la "niña periodista" despertó en Carrillo Puerto lo condujo a traducir el nombre y el apellido de Alma al maya yucateco: Pixan ("Alma") Halal (Reed, "caña” en español), aunque esta pasión tropezaba con el matrimonio de Carrillo Puerto con María Isabel Palma de Carrillo, madre de sus cuatro hijos.

Como resultado directo de las reformas de inspiración socialista promulgadas durante su breve gobierno de sólo veinte meses, medidas rechazadas por la "Casta Divina” y la Iglesia católica, el primer gobernador de Yucatán elegido democráticamente fue ultimado el 3 de enero de 1924, junto con sus hermanos Edesio, Benjamín y Wilfrido, 
y nueve de sus colaboradores políticos, entre ellos, Manuel Berzunza, su principal consejero.

Figura 3. Carrillo Puerto después de ser fusilado, enero de 1924.

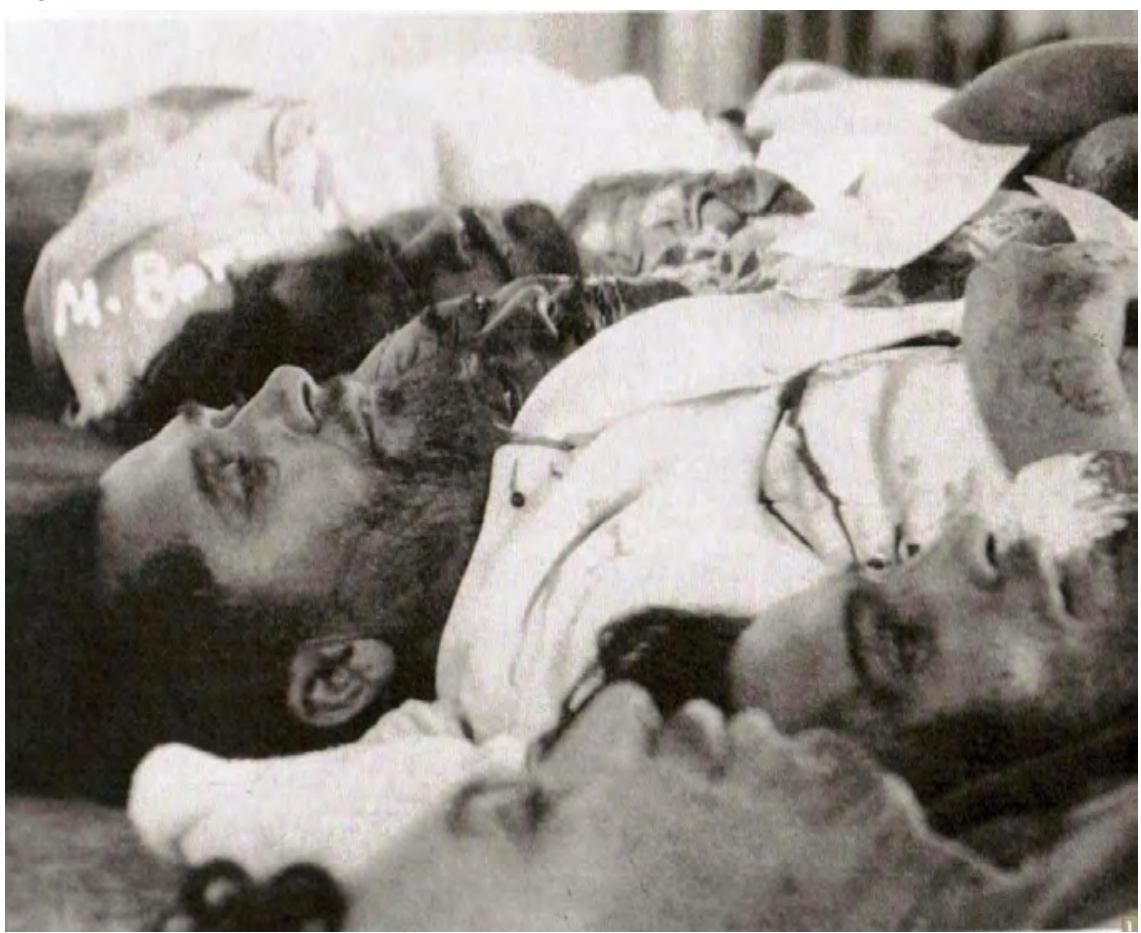

Fuente: En Felipe Carrillo Puerto: iconografía, 1997, Universidad Autónoma de Yucatán, p. 97

Según la autora norteamericana Katherine Anne Porter, Reed fue informada del asesinato de su prometido mientras ensayaba para su boda en el Hotel Fairmont de San Francisco, cuando el recepcionista del hotel le entregó un telegrama con la funesta noticia. Durante su efímero gobierno, Felipe Carrillo Puerto buscó recuperar el pasado histórico de la cultura maya como manera de honrar a sus oprimidos descendientes, gran parte de los cuales vivía y trabajaba en condiciones de miseria en las enormes haciendas henequeneras de su estado. 
Entre otros proyectos, Carrillo Puerto construyó una carretera de Mérida a Chichén Itzá, y llevó a cabo un festival popular para conmemorar su inauguración. Carrillo Puerto también fue un activo partícipe en la recuperación de los vestigios de la cultura maya; como ya se ha mencionado, para facilitar su difusión popular, trasladó sus oficinas del Palacio de Gobierno a la Casa del Pueblo, en virtud de que había transformado el primero en centro cultural y museo arqueológico para el disfrute de los habitantes de Mérida.

Los asesinos de Felipe Carrillo Puerto, de sus hermanos y colaboradores, fueron agentes de la insurrección delahuertista contra el gobierno de Álvaro Obregón dirigidos por el coronel sonorense Juan Ricárdez Broca. Según señala Pedro Castro (2014a) en su artículo "Felipe Carrillo Puerto: la muerte del Dragón de los Ojos Verdes", las razones que eventualmente llevaron al gobernador — después de un juicio espurio llevado a cabo por un consejo de guerra contra un civil-al paredón de fusilamiento son varias y complejas, aunque uno de los motivos más citados por los historiadores radica en las leyes implementadas para expropiar tierras de los ricos hacendados, enemigos de su gobierno algunos; si bien, como señala el investigador:

La llamada ley despojo hizo poner el grito en el cielo también a quienes trabajaban normalmente sus propiedades. Era una raya más al tigre — por decirlo así-, ya que, a pesar de todo esfuerzo, Carrillo Puerto era un pésimo administrador, rodeado de un grupo de allegados familiares y compadres sin más miras que llenarse los bolsillos. Sus excesos retóricos, combinados con un mercado internacional del henequén en picada a consecuencia del fin de la Primera Guerra Mundial, eran motivo de enojo y preocupación para muchos, y desde luego para el gobierno obregonista.

En este ambiente, la ley despojo causó serios temores a muchos grandes propietarios, ante la posibilidad imaginada de que fuera el primer paso hacia la socialización de los medios de producción. En particular, la "casta divina" — término acuñado por el general [Salvador] Alvarado para designar a las familias henequeneras más rancias- no olvidaba que la Guerra de Castas del siglo apenas 
anterior las puso al borde de su eliminación física, y dadas la situación de pobreza y el resentimiento indígena, solamente faltaba la chispa que prendiera la pólvora, y ese podría ser Felipe Carrillo Puerto (Castro, 2014a: 196).

Después de la muerte de Felipe Carrillo Puerto, Reed viajó al norte de África como corresponsal de The New York Times. Desde ahí escribió sobre las excavaciones en Cartago llevadas a cabo por un noble polaco, Byron Kuhn de Prorok. En 1927, Reed viajó a Grecia, donde se reunió con su amiga de la infancia, Eva Palmer, esposa del célebre poeta griego Ángelo Sikelianós, cuya obra Alma tradujo al inglés bajo el título Dedication. Durante su estancia en Atenas, Alma participó en el primer Festival Délfico, organizado por sus amigos como proyecto de restitución de la cultura griega a sus verdaderos herederos. Reed y Palmer viajaron después a Nueva York, en ese mismo año, para fundar la primera colonia norteamericana de la Sociedad Délfica.

En los primeros meses de 1928, las dos amigas alquilaron un departamento en el Greenwich Village de Manhattan que fue bautizado como "El Ashram", en homenaje a Mahatma Gandhi, a quien Reed y Palmer tanto admiraron. Como la colonia de Gandhi, su sociedad giraba alrededor de actividades comunales, y al mismo tiempo servía como centro de un movimiento cultural basado en la filosofía antigua.

Cierto día, Reed recibió un telefonema de Anita Brenner, joven escritora de ascendencia judía nacida en Aguascalientes, apasionada también de todo lo mexicano. Ella le informó que José Clemente Orozco vivía en Manhattan desde diciembre de 1927 y estaba un poco desanimado pues no lograba entrar al mundo del arte de Nueva York. Reed, que había admirado sus asombrosos murales en la Escuela Nacional Preparatoria durante su primera visita a la capital en 1922, inmediatamente ofreció su ayuda y lo fue a visitar en su modesto estudio.

Poco después, Reed convenció a su amiga Eva Sikelianos para que aceptara ser pintada por Orozco; éste rápidamente dispuso su caballete en un pequeño espacio que él nombró como "La Pulquería". 
Figura 4. Fiesta en Delphic Studios, Manhattan, 1936. De izq. a dcha.: David Alfaro Siqueiros, Kahlil Gibran, Alma Reed, y José Clemente Orozco.

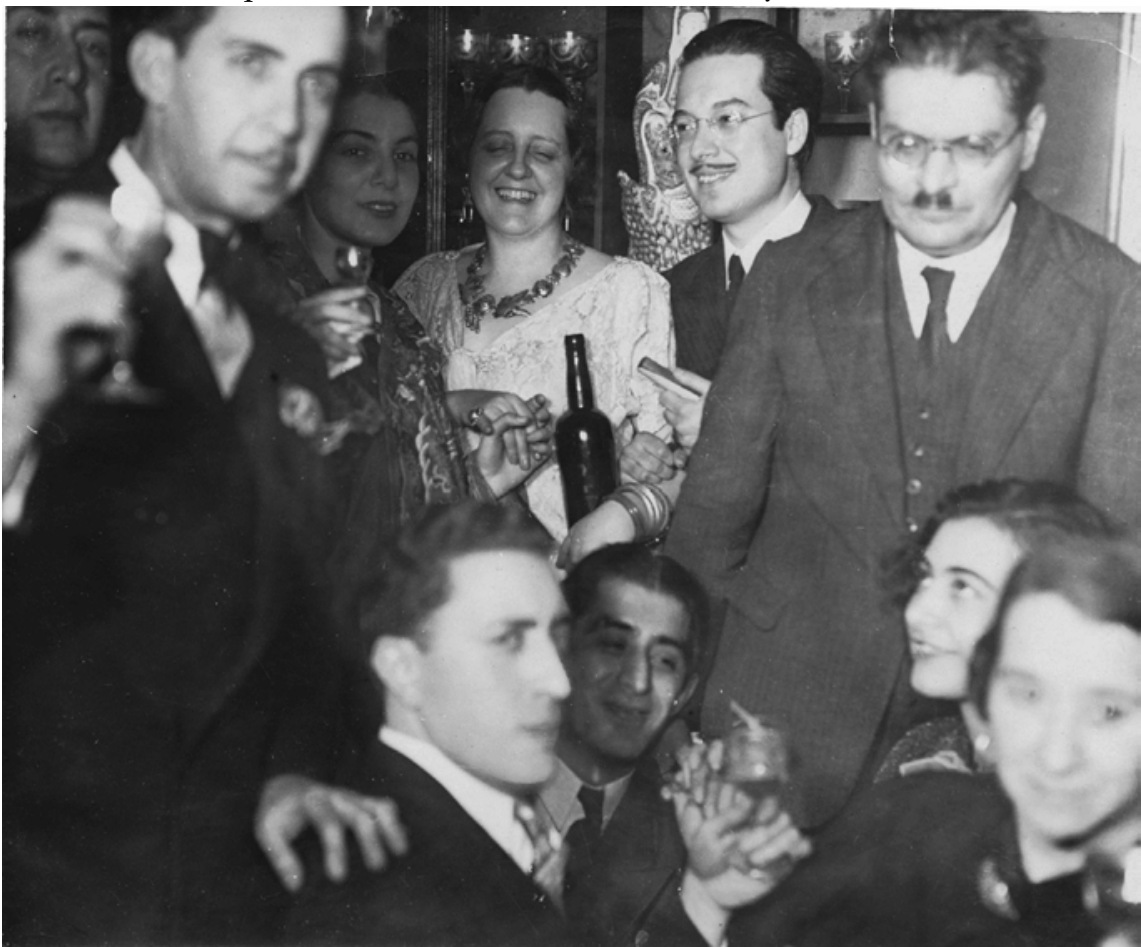

Fuente: Cortesía de "Enrique Riverón Papers, 1918-1994", en Archives of American Art, Smithsonian Institution

Gracias a Reed, Orozco inauguró en septiembre de 1928 su primera exposición en Estados Unidos en el departamento neoyorquino. Más adelante, con el producto de la venta de una propiedad suya en San Francisco, Reed pudo alquilar un local en la calle 57 de Manhattan y establecer ahí su propia galería dedicada — al principio- exclusivamente a Orozco, y después a otros artistas mexicanos.

El "crack", o gran debacle financiera de 1929, que alteró la vida económica norteamericana, significó también un declive en la relación profesional entre Reed y Orozco. No obstante, poco después —en 1930 - Reed logró que le encargaran a Orozco un mural en el refectorio del Pomona College, ubicado cerca de Los Ángeles, California. El título de esa obra: "Prometeo encadenado", fue inspirado por Alma 
así como por los amigos e ideas que había adquirido Orozco en la Sociedad Délfica. Reed también consiguió que le solicitaran otro mural para la New School for Social Research de Manhattan, inaugurado en 1931, cuyo panel principal se titula "Mesa de Fraternidad". Entre las imágenes incluidas en el mural, se encuentra un retrato de Felipe Carrillo Puerto, inspirado en una foto que el gobernador mártir le había regalado a Alma, su prometida, tiempo atrás.

En 1932, Orozco fue invitado a pintar su último mural en los Estados Unidos, esta vez en el Dartmouth College, ubicado en el estado de New Hampshire, mismo que el artista tituló como "Prometeo indiano”. Ese año Reed publicó su primer libro sobre Orozco y, a lo largo de más de tres décadas, escribió otras obras dedicadas a México, a su arte y sobre todo a su arqueología. Sobresalen The Mexican Muralists (1961) y El pasado remoto de México (1966).

Además de sus varios libros, Reed fue una conferenciante incansable que daba a conocer aspectos importantes de la cultura mexicana a estadounidenses ávidos de saber más sobre su, a veces temido y siempre malentendido, vecino del sur. Alma Reed, ya una mujer madura de 63 ańos, volvió en 1952 para quedarse por siempre en su amado México, donde todavía era una leyenda viva y en donde era costumbre que los músicos locales interpretaran la balada compuesta en su honor cada vez que ella llegaba a un restaurante o evento cultural.

En cuanto Reed llegó a la Ciudad de México, Rómulo O’Farril, dueño del periódico Novedades, la contrató como columnista en el recién fundado diario The News, que se publicaba en inglés. Escribía una columna semanal bajo el título "Alma M. Reed Reports" en la edición dominical de ese rotativo, así como lo había hecho para The New York Times durante el lapso en que escribió varios artículos en el suplemento dominical The Sunday Magazine, casi siempre dedicados a la arqueología mesoamericana prehispánica así como a la grecolatina. La incesante dedicación de Alma Reed a México y su cultura no pasó inadvertida para las autoridades mexicanas y, en 1961, se convirtió en la sexta mujer condecorada con la Órden del Águila Azteca en reconocimiento a 
su destacada contribución a la cultura mexicana durante un periodo de casi medio siglo. ${ }^{3}$

Ese año fue determinante para Reed, pues también publicó The Mexican Muralists (Los muralistas mexicanos), un importante estudio sobre el renacimiento de la pintura mural mexicana, y fue condecorada con la Órden de la Beneficencia de la República Griega, en reconocimiento de su contribución al rescate de la cultura clásica griega por medio de la fundación de la Sociedad Délfica en Nueva York y de sus traducciones al inglés de la poesía de Ángelo Sikelianós.

Unos días después de que los resultados de una cirugía exploratoria le revelaran un cáncer intestinal diseminado, Alma Reed, "La Peregrina”, falleció el 20 de noviembre de 1966, día del aniversario de la Revolución mexicana.

En palabras de su querido amigo, el periodista norteamericano radicado en México, Joe Nash: "Si ella hubiera podido escoger una fecha para terminar su carrera de militante, habría sido precisamente esa”. Por petición suya, el monumento funerario de Alma Reed fue erigido enfrente de la tumba de Carrillo Puerto en el Cementerio General de Mérida, bajo el amparo de un enorme árbol y separado de su gran amor por un sendero.

Uno de los lados del pedestal labrado en piedra rosa lleva el siguiente epitafio: "Alma Reed: Escritora fecunda, conferencista emotiva, amó entrañablemente a México y México la honró con el Águila Azteca en reconocimiento a sus méritos como impulsora del arte, como crítica, historiadora y humanista. Grecia y Líbano la distinguieron también, imponiéndole sus más altas condecoraciones".

\footnotetext{
${ }^{3}$ La aviadora Amelia Earhart y la cantante de ópera Grace Moore recibieron la condecoración del Águila Azteca antes que Alma Reed.
} 
En agosto de 2001, entre almohadas y cobijas envejecidas, dentro del clóset de un departamento abandonado de la ciudad de México, y sepultado en un sabucán de henequén, descubrí la copia mecanografiada de la autobiografía de Alma M. Reed: una historia de amor, política y sueños utópicos compartida por dos figuras contrastantes pero imprescindibles de la época postrevolucionaria en Yucatán. Este material había desaparecido desde 1966, cuando falleció su autora, conocida en México como "La Peregrina", la "de ojos claros y divinos", como reza la balada compuesta en su honor. Después de treinta y cinco años de haber languidecido en ese clóset capitalino, mucho me complació —en 2006 - publicar el apasionante relato de la vida de una norteamericana que se entregó en cuerpo y alma a México y a su violentamente truncado "idilio socialista" con Felipe Carrillo Puerto, en sus palabras: el "Abraham Lincoln de México".

Pero hubo más en ese deshilachado — mas sumamente pródigosabucán verde: entre los fólderes que contenían las páginas manuscritas de su autobiografía había un sobre con una etiqueta que decía "Letters and Maya Poem" ("Cartas y poema maya"). Al inspeccionar su contenido, me encontré con doce de las cartas que Felipe había enviado a Alma durante la intensa relación epistolar que sostuvieron de marzo a diciembre de 1923, con un lapso en septiembre de ese año al estar juntos en la Ciudad de México. El poema resultó ser la letra de la canción "La Peregrina", traducida al maya, algo que me confirmó el Dr. Ramón Arzápalo Marín, de la UNAM, experto en maya yucateco. La primera vez que me dispuse a leer estas cartas me sentía como un intruso, ante mis ojos discurrían las apasionadas palabras de Felipe - mecanografiadas con tinta roja en papel membretado del Partido Socialista del Sureste- que expresaban su profundo amor por Alma, su deseo de mejorar el estado de sus "inditos" y de iniciar una vida conyugal con su enamorada en Mérida. 
Figura 5. Carta enviada por Felipe Carrillo Puerto a Alma Reed, 10 de junio de 1923.

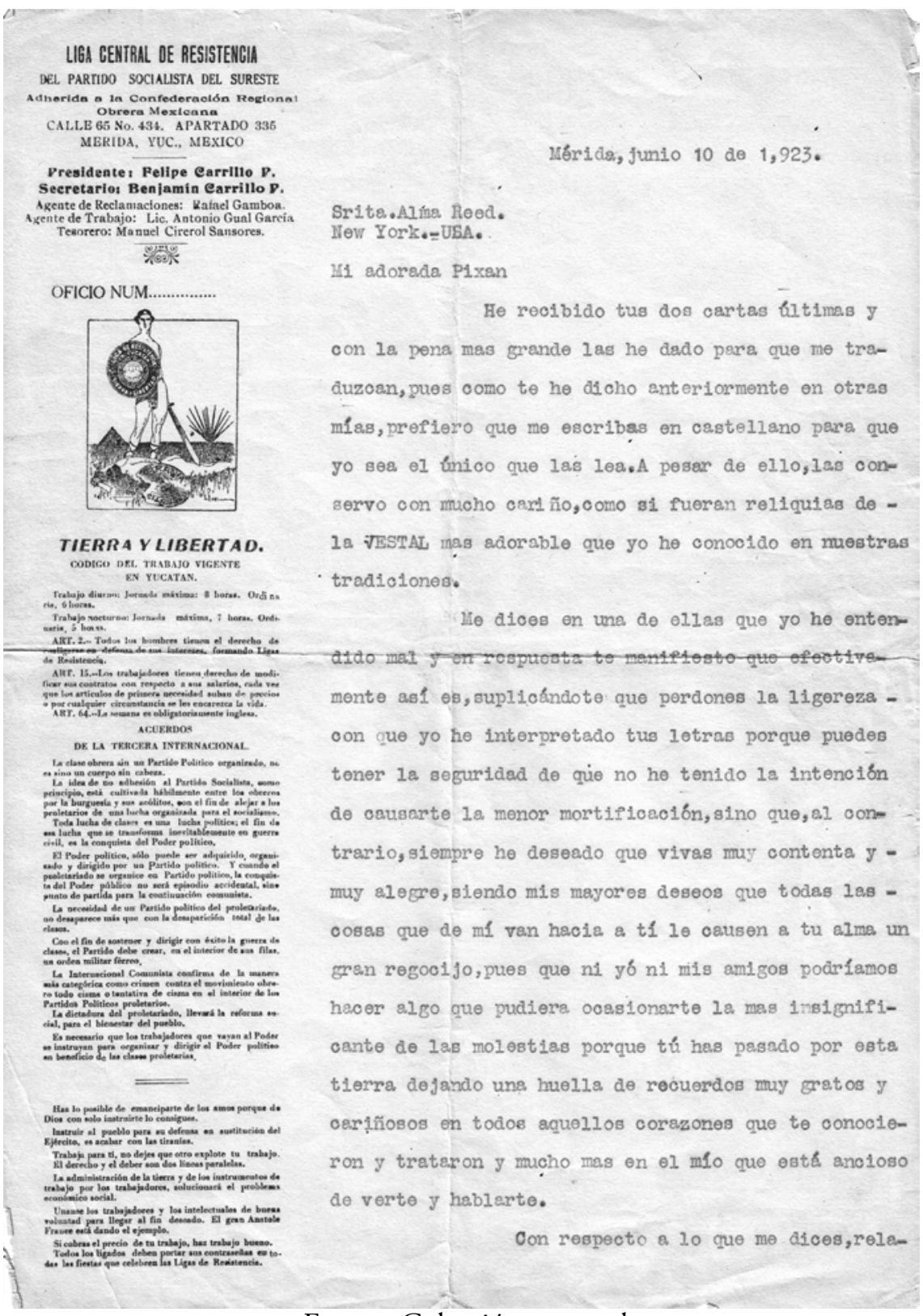

Fuente: Colección personal 
Sin embargo, no todas eran cartas de amor apasionado. También Felipe le comunica la información que Alma le pide sobre los recientes hallazgos arqueológicos, la creación de la "Casa del Nińo" — la cual ella cree que se inspira en La República de Platón-y el estatus de las modernas leyes de divorcio instituidas por su comprometido — esto antes de haber conocido a "la flor más bella del norte".

Si bien utilicé la información que contienen estas cartas para la redacción que escribí de un estudio preliminar a la autobiografía de Reed, y también reproduje algunas de ellas de manera facsimilar en dicho volumen, no se me ocurrió la idea de publicarlas de manera independiente hasta que — hará ya unos once años — se murió Rosalie Johansson, pintora sueca radicada en México desde los años cincuenta y compañera de piso de Alma hasta su muerte en noviembre de 1966. Yo la había entrevistado en varias ocasiones y ella me complació con detalles sobre la vida de su admirada amiga: Rosalie decía que me consentiría por tener yo sangre sueca.

Además, y para mi gran sorpresa, la maestra conservaba la última versión de la autobiografía de Alma, la cual me permitió fotocopiar para cotejarla con la que yo había encontrado, que resultó ser incompleta porque le faltaban los últimos tres capítulos. Lo que nunca me dijo la excéntrica octogenaria era que, aparte del bustito de bronce de Alma que se alzaba orgullosamente sobre la chimenea de su casa y una caja de fotos de "La Peregrina" que guardaba dentro de la misma chimenea, también resguardaba en ese pequeño departamento de la calle Río Sena esquina con Río Balsas cajas de recortes periodísticos organizados meticulosamente por Alma en antiguas carpetas de cartón negro, maletas llenas de ropa — vestidos largos, guantes de seda, sombreros (éstos tenían sus propias maletitas octagonales), archiveros con correspondencia de prácticamente todas las figuras del mundo artístico mexicano (Frida, Diego, Rufino, José Clemente, etcétera), bisutería, cuadros de Carrillo Puerto y retratos de Alma pintados por amigos, incluyendo el de Johansson.

Nunca comprenderé por qué la pintora sueca decidió no compartir este tesoro conmigo en vida. Cuando murió en 2004 llamé a la Embajada de Suecia en México para informarles que Johansson tenía fotos y 
un busto de Alma Reed, "La Peregrina”, y que sería indicado que estos invaluables objetos llegaran al Museo Nacional de Historia, Castillo de Chapultepec, donde hacía ya muchos años la imprevisible sueca había enviado algunas pertenencias de su amiga. Unas semanas después fui al museo y, para mi sorpresa y alegría, estos objetos - y muchos, pero muchos más_ habían llegado a su destino. De hecho el donativo que hicieron las sobrinas de Johansson colmaba un pequeño cuarto del Castillo de Chapultepec.

Después de llevar a cabo una inspección detallada de esta insólita colección con mi colega Amparo Gómez Tepexicuapan, investigadora del recinto, encontramos - celosamente guardadas en un antiguo archivero de metal durante más de setenta y cinco años- muchas más cartas, unas cincuenta y cuatro en total. También descubrimos más de cuarenta telegramas enviados a Reed por Carrillo Puerto durante su efímero romance. Pero eso no era todo: de alguna manera, y debo confesar que no sé bien cómo, después de su asesinato y el caos que siguió en Yucatán, Alma logró recuperar diecisiete de las cartas que le había enviado a Felipe durante su breve romance. Me imagino que las recuperó por medio de Elvia, hermana de Felipe, porque la única misiva en la colección que no es de Felipe Carrillo o Manuel Cirerol Sansores, un colaborador suyo, es de la llamada "monja roja del Mayab", como la bautizó Monique Lemaitre en su libro dedicado a esta feminista avant la lettre.

De la manera que haya sido, gracias a este esfuerzo de Alma, contamos con un epistolario dialógico en el sentido de que se conservan las cartas de ambos personajes — remitente y destinatario_-, lo cual hace de su lectura algo singular porque de esta manera se puede atestiguar cómo va creciendo su amor, sus sueños, sus ideas progresistas y los planes que tenían para vivir juntos en Villa Aurora, su casa conyugal — aún conservada - en Mérida. Otro aspecto significativo de esta correspondencia: en algunos casos donde Felipe le menciona que incluye las fotos que Alma le solicita en el sobre que contiene la carta, pudimos localizar esas imágenes que ahora forman parte de la gran colección de fotografías y otros documentos que conserva el Museo Nacional de Historia y que incluimos en nuestra edición del epistolario. 
Un detalle interesante: por medio de las cartas de Alma, se puede atestiguar cómo y con qué velocidad Pixan — que así le decía Felipe- va aprendiendo el castellano, idioma que al principio le presenta ciertos obstáculos y no poca pena. Como ejemplo, aquí transcribo un fragmento de la primera, enviada desde Nueva York el 8 de marzo de 1923 y pergeñada con pluma fuente sobre papel membretado con las iniciales AMSR (Alma Marie Sullivan Reed):

\section{Dragonito Encantador:}

Por favor, señor, lea Ud. estas paucas líneas sin ayuda... si posible... Su cablegrama de Ud. era la causa de gran felicidad a mí... Y también las otras, que yo recibo cada noche de los rayos de la luna. Yo estoy muy contenta que Ud. piensa de mí después de todos estos días... ¿Es verdad que Ud. quiere? [...] Ud. es en mi pensamiento mucho, y más y más yo tengo admiración de su sinceridad en la causa de sus pueblos, y para su nobilidad de carácter. Naturalmente, no es posible aceptar todas sus ideas modernas, pero yo creo con todo $\mathrm{mi}$ corazón que Ud. es un hombre con un gran visión para su país y la raza humana... Y muy importante, especialmente para periodistas americanas, y más peligroso, Ud. es un dragonito encantadoro, y un poeta con toda la belleza de la vida en su alma... Nunca olvidaré estos hermosos días en Yucatán, cuando Ud. y yo ví las ruinas mayas, los pueblitos, (especialmente Kanasín), y todas las otras cosas bonitas de Mérida... (Schuessler y Gómez, 2011: 40).

Por su parte, a lo largo de la correspondencia, Felipe le comenta a Alma que está aprendiendo inglés. Según le escribe en una carta fechada el 17 de marzo de 1923; cito: "porque deseo hablar contigo en tu idioma, porque deseo conocerte tal como eres, y espero que después de que conozca algunas palabras, vengas tú a enseñarme mejor y entonces ese día será el más feliz de mi vida" (Schuessler y Gómez, 2011: 80). Nunca logra su cometido y — tal vez por eso y por su propia naturaleza— sus cartas son verdaderos alardes pasionales, pero también receptoras de sus sueños, sus proyectos, de su ser más íntimo. 
Al mismo tiempo, al gobernador socialista de Yucatán no le gustaba que Alma escribiera sus misivas en inglés, prefería su elemental español. En una carta fechada el 13 de mayo del año en cuestión, la recrimina y no sólo por su elección de idioma:

Veo que escribes tus cartas en español con vacilación, quizás piensas que no están perfectamente bien escritas, pero te aseguro que eso es un error, pues son muy claras y comprendo todo lo que me dices. Sin embargo - continúa - lamento que no digas nada respecto a los sentimientos de tu alma. Tu maravilloso poder de razonamiento guía todas tus afirmaciones. Sabes perfectamente que cuando la conciencia habla, el corazón calla; tu corazón es indiferente, yo te importo poco y esa es la razón por la que amas más a tus periódicos. Ellos son todo para ti: libertad e independencia; [...] Conmigo es distinto, pues a pesar de que amo profundamente a mi pueblo indio, te amo más a ti, pues a pesar de tu inteligencia eres una escritora mal pagada de un periódico que explota tu inteligencia y tu belleza para hacer dinero, dinero del cual, estoy seguro, tú no participas más que en pequeńa cantidad. [...] De ahora en adelante, todas mis cartas van a estar dirigidas a la editora Alma Reed, para que ella esté enterada de las cosas que estamos haciendo aquí para beneficio de toda la humanidad. [...] Con todo el afecto de mi alma, que no puede olvidarte, te envío mi despedida, Srita. Gerente (Schuessler y Gómez, 2011: 127-128).

Si bien es cierto que la mayoría de estas cartas se enfoca en la relación sentimental que floreció entre un gobernador yucateco y una periodista estadunidense, hecho que podría hacer cuestionar el valor historiográfico que posee esta colección epistolar de indiscutible índole personal, también se deja entrever entre sus páginas algunos pasajes en los que Carrillo Puerto le narra a su enamorada los asuntos políticos locales y nacionales más importantes del momento. De hecho, es precisamente en estos fragmentos donde el "Dragón Rojo" se expresa de manera franca y sin disimulos sobre los acontecimientos políticos en los que se encuentra inmerso en aquel momento, comentarios que 
muchas veces sirven de contrapunto para rellenar los intersticios de la historia oficial y el mito personal que se construiría alrededor de su figura después de su muerte. Muchos de estos comentarios, que se descubren entre párrafos apasionados en los que Felipe declara un amor absoluto y profundo por su "niña periodista", o se queja de su prolongada ausencia, se enfocan en los enfrentamientos políticos nacionales que - vistos a posteriori- son el preludio de la tragedia personal y sublevación política que se avecina en Yucatán, algo que Alma parece sentir con más presciencia mientras se aproxima el trágico desenlace. Un ejemplo representativo de este tipo de carta se encuentra en una larga misiva que Felipe le manda a Alma el 25 de noviembre de 1923, aproximadamente un mes antes de su muerte. En ella, el gobernador intercala los estremecimientos íntimos que le incita su enamorada con un sobrio apartado dedicado a los eventos políticos más relevantes del momento. Parece ser, en realidad, una concesión, gracias a las peticiones de la propia Reed, quien como buena reportera siempre busca la primicia, en este caso las novedades procedentes de una región que en ese momento se encuentra en medio de un tumulto político que afectará no sólo a la Península de Yucatán sino al país entero:

Mérida 25 de Noviembre de 1923

Alma Primorosa de mi vida:

No te había escrito porque esperaba que estuviera cerca el día de la salida del barco para hacerlo y comunicarte todo lo que estoy pensando, como lo que estoy haciendo, pero anoche he recibido tres bellísimas cartas tuyas, que son del seis, doce y quince del presente; no puedes imaginarte lo feliz que me hacen tus divinas letras, éstas, vida mía no duermen bajo de mi almohada, sino, encima de mi corazón, después de que las lleno de besitos figurándome tu blanca mano encima del papel y tus ojos color de cielo de mi felicidad sobre ellos, y tu pensamiento como tu alma dentro de cada palabra que en ellas están escritas, para este tu pobre dragoncito que se muere de amor por ti. 
Mi reina linda, estoy muy contento porque cada día que pasa, siento que se acerca mi felicidad, a pesar [de] que me parece que los días se hacen interminables y mi desesperación no tiene límites, pero no tengo más remedio que conformarme, porque no lo puedo remediar.

Con respecto a tus temores, no debes ser así como me dices en una de tus cartitas. No te cumpliré mis promesas porque te las hubiera ofrecido, sino porque sin ti, la vida me sería demás, y yo sin tu compañía no serviría de nada en esta tierra, conque ya ves que no sólo por compromiso cumpliré cuanto te he ofrecido sino porque eres imperiosa, tu presencia es de gran utilidad para mí en toda la extensión de la palabra: eres como el tallo a la flor, como el sol a la tierra, sin ti siento que no puedo vivir y, tus solas cartitas me llenan de vida y de entusiasmo por ti [...]

LA POLÍTICA. No se pondrá dura porque han probado ya los callistas que son más fuertes que los contrarios, a pesar que de la Huerta se está portando como todos los cobardes y traidores con las personas que lo hicieron gente. Afortunadamente el General Calles no hace caso y sigue imperturbable su campaña contra toda la opinión de los periódicos huertistas que son los que están haciendo la política de este buen señor; así es que no temo nada y aquí estamos listos para hacer las cosas con toda paz y orden, pues no consentiré se derrame una gota de sangre de mis compañeros en esta política, sólo procuraré que lo que estamos haciendo perdure y defendamos hasta con nuestras propias vidas; así es que mi reina linda debes estar conmigo cuanto antes, para que yo esté más tranquilo y pueda dedicarme con más amor a nuestra causa.

Por razones especiales he retardado hasta el día de ayer la petición de mi divorcio y por eso te telegrafié en el acto, para que tu estuvieras tranquila y no temas nada de lo que dirán los periódicos en contra nuestra, pues de mí sólo santo no han dicho, pero yo vine a este mundo de desventuras a hacer lo que crea debo hacer, y no lo que quiera el público, puesto de mí no ha hecho más que decir lo más malo y nunca concederme el derecho de hacer lo bueno sin embargo que no he hecho otra cosa. 
Desde que te amo con todo mi cariño Pixancita mía, te siento como si fueras mi esposa linda, porque siento que tú también me amabas y que no querías que lo supiera tiernamente como me lo has demostrado en estos últimos días en que has estado a mi lado; ¡y cómo recuerdo esos días tan deliciosos que pasamos! ¡Cómo siento que mi corazón palpita con tanta fuerza cuando te recuerdo, con qué ansiedad te espero para besarte con toda mi alma y con todas mis fuerzas para estrecharte contra mi pecho y adorarte mucho más!

Ven pronto vida mía, ven como vienen las olas del mar a la playa, ven, como vienen los perfumes a las flores, ven, mujercita mía, como vienen los pájaros a sus nidos, ven, vida de mi vida, como una mujer enamorada de su amante, ven que te espero anhelante y lleno de amor para rendirme a tus pies, ven mi vida para que te colme de caricias y seamos felices eternamente, ven para que te dispute al mundo si él te pretende arrebatar de mis brazos. Me siento tan feliz ahora que puedo ofrecerte mi vida en holocausto de tu amor, por eso te deseo mucho más, por eso te amo con vehemencia loca, todo mi cuerpo eres tú, tú siempre, siempre tú serás mi existencia adorada mía... Tuyo como siempre inalterable para nuestro amor, Felipe [firma]

(Schuessler y Gómez, 2011: 285-287).

Los lamentos de Felipe se menguan y se vuelven a manifestar — como en cualquier relación-, pero la esperanza muere a lo último, y a lo largo de casi un año nosotros, lectores cómplices — tal vez intrusos-, atestiguamos el nacimiento de un profundo amor, un respeto mutuo, un sueño compartido para mejorar la raza humana. En su última carta, fechada el 10 de diciembre de 1923, a menos de un mes de su ignominiosa muerte, Felipe no olvida su futuro con Alma, si bien el presente está lleno de peligros e incertidumbres:

Alma mi niña linda:

Tanto tiempo hace que no tomo la máquina para escribirte; hasta 
que en esta noche que son la una y cuarto, he tenido tiempo para dedicarle a mi esposita adorada estas cuantas letras.

Desde que el malhadado de De la Huerta se le ocurrió presentarse como primer jefe de la revolución contra el Gobierno constituido, hasta este momento que puedo venir a mi casa que es la tuya con todo anhelo, a esta hora para descansar y dedicarte mis pensamientos y mis carińos en esta carta. He organizado a todo el Estado en un cuerpo Rojo de guerra para defender en cualquier momento nuestras libertades como lo poco que hemos ganado en las cuestiones económicas y sociales, he arengado al pueblo y con ejemplos les he hecho comprender la necesidad que tienen de formar estos Batallones Rojos de defensa para que los soldados de la reacción no nos arrebaten nada de lo que tenemos y sólo me desespera la falta de armas y parque para darles a éstos mis pobres inditos que ansiosos me lo piden.

He enviado a Manuel a ese tu país para ver si puede comprar los rifles y ametralladoras que deseo para defendernos de los ambiciosos que no tienen más religión que la ambición como lo ha demostrado esta vez De la Huerta y el grupo de oportunistas que lo han secundado; afortunadamente no les durará mucho tiempo ésta su hazaña que con tanto descaro se ha hecho.

Esta tu casa, está como un cuartel, un grupo de amigos me acompañan y un piquete de fuerzas de la policía la resguarda, por lo que pueda suceder, en este momento que no tenemos de quién confiar, pues cuando menos lo piensa uno tiene de amigo algún traidor vestido de socialista, que sólo está con nosotros por lo que puede sacar, pero especialmente los llamados militares que estos también no sabe uno cuándo le van a asesinar por las espaldas, afortunadamente tengo aquí un coronel Robinson que es muy afecto a nuestra causa y sólo por él no hubo aquí un zafarrancho de esos desesperados. Hasta anoche tuvimos que arreglar con el Jefe de las fuerzas de Campeche ciertas bases para que este Jefe de Operaciones no reconociera a Huerta, ya puedes figurarte como he estado de atareado y preocupado de salvar nuestro partido que tantos sufrimientos nos cuesta. 
$\mathrm{Y}$ en medio de estos trabajos cruentos y desesperadamente activos, en mi imaginación estabas siempre, tú mi Adorada Alma, si tú supieras cómo deseo que estés a mi lado, sólo porque amo mucho con toda mi sangre esta tierra, no la abandono, porque es una injusticia de los hombres, llevar a los hombres a la guerra por asuntos personales y egoístas como el que tenemos ahora. Siento que yo no nací para esta época, ni para esta tierra llena de ambiciosos y de inhumanos, y, sólo porque siento a tu alma dentro de la mía, no me elimino de este mundo tan ingrato y tan terrible; pero te prometo, que después de este movimiento si salimos con bien, me dedicaré a proporcionarle a cada hombre un rifle y después de conseguirlo, entonces abandonaré ésta mi tierra y me iré a cualquier lugar desconocido para mí y allí vivir como pueda, y si tú eres mi linda compañera, dedicarme a ti, para hacerte más bella, más buena, y más amorosa para que vivamos una vida de las flores y de los pájaros; ¿Te gustaría mi Reina linda vivir así como yo deseo?

Hasta otra vez, porque esta carta fue interrumpida a las dos de la mańana y la cierro a las ocho y media del día siguiente. Una bomba explotó en la calle 68 frente a la casa de un doctor Caamal.

Con todo mi carińo te envío recuerdos y espero que tú pienses, lo desgraciado que soy sin ti a mi lado, no tengo ningún consuelo, ni una caricia la más insignificante. Recibe todos los besos de mis labios y todo el amor de este pobre hombre sediento de felicidad.

Tuyo hasta que me muera.

Felipe (Rúbrica)

PD: Comunícame en aerograma lo nuestro nada más mientras te envío clave (Schuessler y Gómez, 2011: 358-360). 


\section{Bibliografía citada}

Castro Martínez, Pedro, 2014a, "Felipe Carrillo Puerto: la muerte del Dragón de los Ojos Verdes", Iztapalapa. Revista de Ciencias Sociales y Humanidades, año 35, núm. 76, enero-junio, pp. 189-208.

Castro Martínez, Pedro, 2014b, "La apropiación simbólica de lo indígena por el estado posrevolucionario: el caso del cenote sagrado de Chichén Itzá", Boletín del Fideicomiso Archivos Plutarco Elías Calles y Fernando Torreblanca, núm. 76, mayo-agosto.

Lemaitre, Mónica, 1998, Elvia Carrillo Puerto: la monja roja del Mayab, Ed. Castillo, México.

Reed, Alma, 2006, Peregrina: mi idilio socialista con Felipe Carrillo Puerto, Diana, México.

Schuessler, Michael y Amparo Gómez Tepexicuapan (editores), 2011, Tuyo hasta que me muera... Epistolario de Alma Reed (Pixan Halal) y Felipe Carrillo Puerto (H'Pil Zultulché), marzo a diciembre de 1923, Conaculta, Col. Memorias Mexicanas, México.

Walsh, Thomas F., 1992, Katherine Anne Porter and Mexico: The Illusion of Eden, University of Texas Press, Austin.

Willard, T.A., 1926, The City of the Sacred Well: Being a Narrative of the Discoveries and Excavations of Edward Herbert Thompson in the Ancient City of Chichen Itza, The Century Company, New York and London. 